\title{
GPS measurements of horizontal deformation across the Lai Chau-Dien Bien (Dien Bien Phu) fault, in Northwest of Vietnam, 2002-2004
}

\author{
Chi Cong Duong*, Hong-Sic Yun, and Jae-Myoung Cho \\ Department of Civil and Environmental Engineering, Sung Kyun Kwan University, Suwon, Korea \\ (Received April 29, 2005; Revised November 20, 2005; Accepted November 25, 2005; Online published May 12, 2006)
}

\begin{abstract}
Global Positioning System (GPS) measurements from Feb. 2002 through Mar. 2004 were used to estimate the recent crustal movement along the Lai Chau-Dien Bien (Dien Bien Phu) fault (LC-DBF) system in the Northwest of Vietnam. Four GPS campaign data were processed to estimate ITRF2000 and local horizontal velocities, as well as extensive and compressive strain rates across the LC-DBF. ITRF2000 velocities are consistent with east-southeastward movement of Sundaland i.e. Indochina. Local velocities did not reveal much left-lateral strike-slip of the fault system and the derived strain rates were insignificantly different from zero at $95 \%$ confidence.
\end{abstract}

Key words: Crustal deformation, GPS, Southeast Asia.

\section{Introduction}

About $500 \mathrm{~km}$ in length, the Lai Chau-Dien Bien (Dien Bien Phu) fault (LC-DBF) stretches from its nearest point to the Red River fault-north of Chieng Chai Village (Vietnam-China border), through Lai Chau, Dien Bien Provinces in Vietnam, to its end in Louang Phrabang Province in Laos (Lacassin et al., 1997; Holt et al., 2000; Burchfiel, 2004). Its part in Vietnam is approximately 160 $\mathrm{km}$ long and 6-10 km wide (Figs. 1 and 2).

During the Cenozoic, the LC-DBF passed two main tectonic development stages, which are characterized by rightlateral and reverse right-lateral strike-slip and by left-lateral and normal left-lateral strike-slip mechanisms, respectively. The boundary between these two stages was possibly in Pliocene (Lacassin et al., 1997; Nguyen Van Hung and Hoang Quang Vinh, 2001). A tectonic map of the eastern part of the Tibetan plateau and adjacent areas from the late Cenozoic to recent time from Burchfiel (2004) also shows that the LC-DBF belongs to the left-lateral strike-slip faults.

There are some evidences of recent activity of the LCDBF at a local scale: 1) Earthquakes have been occurring along the fault zone and in its adjacence, and most of them have reached magnitudes larger than 4.0 Richter (Fig. 2); 2) Sources of thermal water have become exposed on surface near the fault zone: for example, in the northwest of Muong Pon Village and Dien Bien Town; 3) The geothermal and geochemistry values of emanation (of $\mathrm{Ra}, \mathrm{Hg}, \mathrm{CO}_{2}$, $\mathrm{CH}_{4}$ ) show high anomalies in Lai Chau Town, Na Pheo Village, etc.; and 4) Landslides and accompanying mudflows

* Permanent address: Laboratory of Geodynamics, Institute of Geological Science, Vietnamese Academy of Science and Technology, Hanoi, Vietnam.

Copyright (c) The Society of Geomagnetism and Earth, Planetary and Space Sciences (SGEPSS); The Seismological Society of Japan; The Volcanological Society of Japan; The Geodetic Society of Japan; The Japanese Society for Planetary Sciences; TERRAPUB. have been occurring frequently, which sometimes lead to disasters like those in 1996 and 1997 at Muong Lay Town (Nguyen Van Hung and Hoang Quang Vinh, 2001).

Before 2002, some geodetic results concerning the Xianshuihe-Xiaojiang fault system and the Red River fault contiguous to the LC-DBF were reported. King et al. (1997) showed the result of analysis of 2-4 year GPS data, which were consistent with the left-lateral slip of $12 \pm 4$ $\mathrm{mm} / \mathrm{yr}$ on the Xianshuihe-Xiaojiang fault system. Analyzing GPS measurements collected in 1994, 1996, 1998 and 2000, with ties in 2001, in Yen Bai, Phu Tho, Vinh Phuc, Ha Tay Provinces in Vietnam, Feigl et al. (2003) conclude that at the local scale, the Red River fault did not slip faster than 1 or 2 mm/yr between 1994 and 2001.

This paper shows initial three-year (2002-2004) GPS measurements and results from processing these measurements in a local-scale network spanning the LC-DBF zone in the Northwest of Vietnam. These geodetic results will give a preliminary and quantitative assessment of recent activity of the LC-DBF for earthquake forecast and natural hazards prevention.

\section{Data Precision and Estimation Strategy}

Our geodetic network covered an area of about 100 $\mathrm{km} \times 20 \mathrm{~km}$ along the LC-DBF. It included 7 stations listed by the name of the main benchmark from north to south: NGA1, DON1, HAM1, LEM1, TAU2, TAU1, TAT1. These stations were distributed regularly along the major fault (Fig. 2). Each station had at least 2 benchmarks: the main one was numbered 1 , and the auxiliaries were numbered 2, 3, etc., except TAU1 and TAU2. Benchmarks were stainless steel cylinder pins built in bedrock wherever possible. LEM2 was the 3rd, HAM2, and TAU1 were the 4th order points belong to the GPS network of Geodetic Survey of Vietnam. Their composition included concrete with porcelain mark on it.

GPS measurements were carried out in 4 campaigns from 


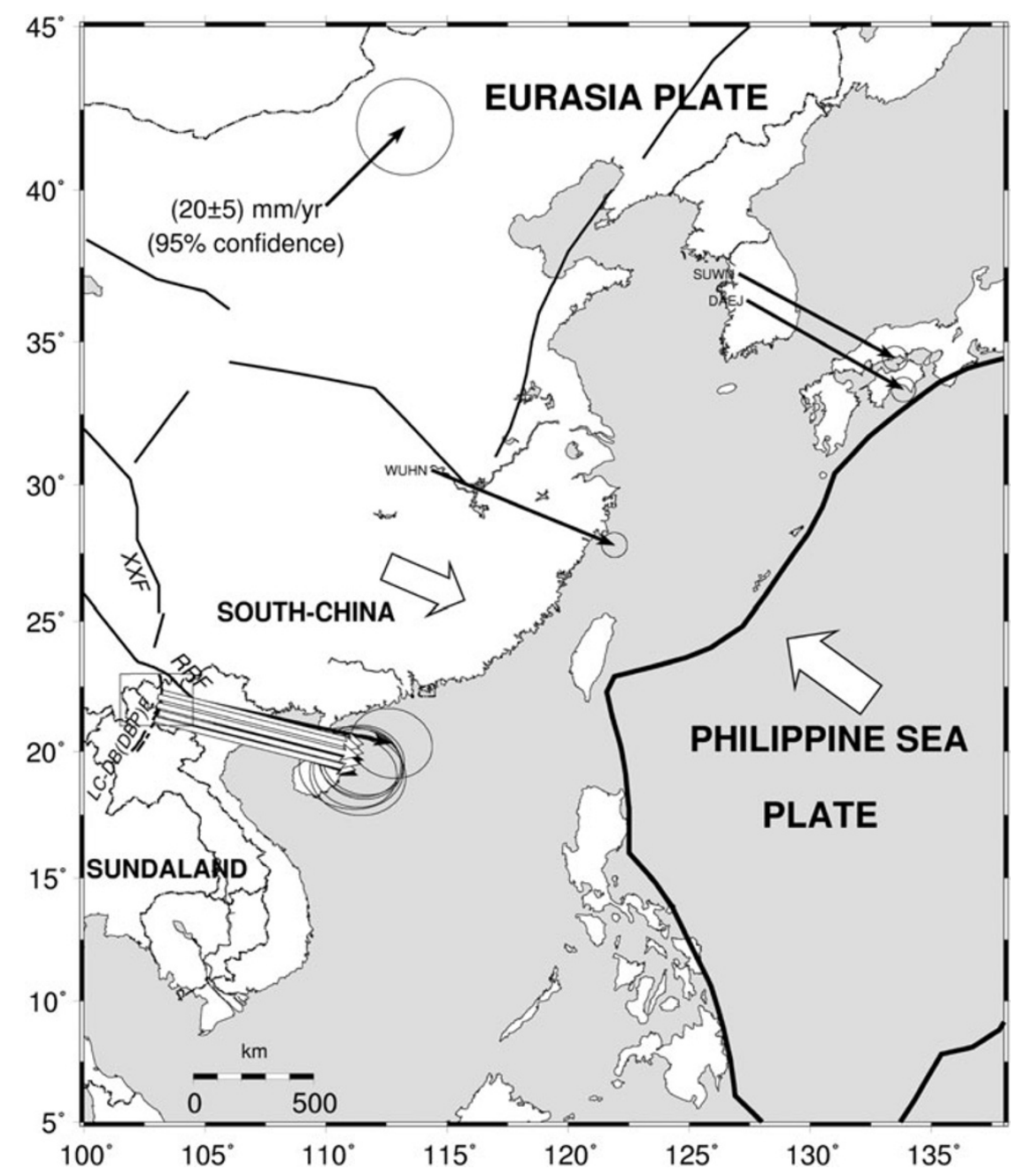

Fig. 1. Vietnam and adjacent region. Heavy lines with thickness gradually reducing show plate boundary and faults by their size; XXF: Xianshuihe-Xiaojiang Fault, RRF: Red River Fault; LC-DB(DBP)F: Lai Chau-Dien Bien (Dien Bien Phu) Fault from Lacassin et al. (1997), Holt et al. (2000), and Nguyen Van Hung and Hoang Quang Vinh (2001). Rectangle delimits the study area as shown in Fig. 2. Black arrows with error ellipses represent our ITRF2000 velocity solution, open thin ones are from Sundaland platelet model (Michel et al., 2001), open wide ones depict direction of movements of the Philippine Sea Plate, South-China and Sundaland blocks (Michel et al., 2000, 2001). Thin and dashed lines are rivers and international borders, respectively.

February 2002 to March 2004 in almost the same (dry) season to avoid the influence of local dislocation on benchmarks (Table 1).

4 TRIMBLE SSI, 1 TRIMBLE SSE receivers, COMPACT L1/L2 with Ground Plane antennas, and only 1 MICRO CENTERED L1/L2 with Ground Plane antenna for the 4th campaign were used to record GPS signals. For no concrete pillar in the network, we had to do point centering with a tripod. GPS data sampling rate of $30 \mathrm{sec}$ and $6^{\circ}$ elevation mask were set to obtain more precise upward component (Nguyen Ngoc Lau, 2002a). Each session lasted about $23 \mathrm{~h} 30 \mathrm{~m}$. RINEX transfer, and only simple quality check was run in situ after each session of field campaigns.

GPS observations were analyzed according to standard procedures (King and Bock, 2003; Herring, 2003). First, we used GAMIT software for processing single sessions, including 5 IGS stations: NTUS in Singapore, SHAO (Shanghai) for 2002a experiment, WUHN (Wuhan) in China, SUWN (Suwon), and DAEJ (Daejon) in Korea. These IGS stations were chosen because they were situated in not- so-actively-deforming blocks in the region (Michel et al., 2000, 2001). Their actual ITRF2000 coordinates and velocities were as ties with the global reference frame. We used IERS (International Earth Rotation and Reference Systems Service) Earth orientation parameters and the updated elevation-dependent antenna phase-center models proposed by the US National Geodetic Survey (Rothacher and Mader, 1996; King and Bock, 2003). Some considerable options for every (day) session processing were as follows:

- Appropriate constraint for initial condition and nongravitational force parameters of all satellites,

- Estimate 13 tropospheric zenith delay parameters using default standard tropospheric models (Nguyen Ngoc Lau, 2002b; King and Bock, 2003),

- Use updated elevation-dependent antenna phasecenter model.

The quality of daily solutions can be assessed by evaluating the repeatabilities of RMS of independent baseline components about their mean value, that is mean repeata- 


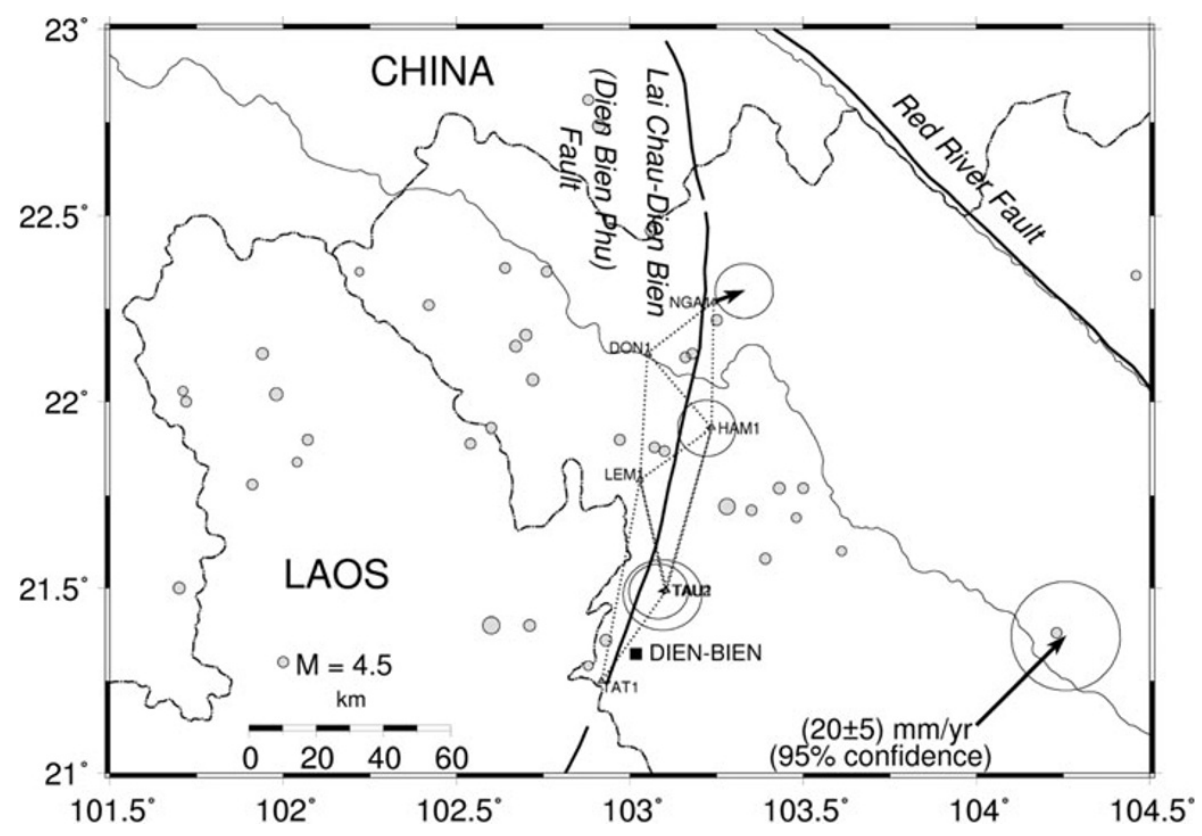

Fig. 2. GPS network with its stations (shaded triangles) and their names, earthquake epicenters (shaded circles) in a study area with magnitude $M>3.5$ from the USGS (US Geological Survey) catalog (1973-Mar. 2005), faults (heavy lines), rivers (thin lines), international borders (dashed lines), and the velocities in a local reference frame defined by DON1, LEM1, and TAT1.

bility (Larson and Agnew, 1991). Mean WRMS for orbit re-estimated, bias-free, and bias-fixed daily solutions are shown for each campaign in Table 2.

There was not so much improvement from bias-free to bias-fixed solutions. Futhermore, WRMS of up components was larger than the one of horizontal components. Of the many effects on the collected GPS data, tropospheric delay, antenna phase center, and orbit errors can explain these differences. Time of sessions for some campaigns, for example, 2002a, was not within the UTC day. This produced a data gap of about half hour because of the reset of the receiver clock. We tried to divide such sessions into subsessions, for example, /055a, /055b etc., but this division did not improve the precision of coordinates and baseline lengths considerably. Therefore, we kept the default 1 UTC day sessions for daily processing. Using an antenna with ground plane could not entirely eliminate the sources of measurement biases. From Table 2, we adopted bias-fixed solutions as a result from GAMIT daily processing for all campaigns.

Second, we applied the Kalman filter (using GLOBK) to combine loosely constrained estimates of station coordinates and orbits with their covariances from each session. For- a small span network and with few permanent IGS stations in an adjacent area, we did not combine our daily solutions with global ones available from SOPAC (Scripps Orbit and Permanent Arrays Center). Maintaining the orientation of our network through IGS orbit and IERS Earth orientation parameters, we followed the iterative process proposed by Herring (2003) to obtain consistent coordinates of all stations for individual GPS network adjustment over each campaign. After time series of coordinates and baseline lengths had been checked for outliers, we excluded NTUS from further velocity solutions because of large RMS of coordinates and baseline lengths associated with it. Precision of baseline length is obtained by the following formula:

$$
\sigma_{\text {length }}=\sqrt{a^{2}+(b L)^{2}},
$$

where values of $a$ and $b$ can be seen from Table 2 , and $L$ is the distance between benchmarks.

These values give an average relative precision of $10^{-7}$ for the shortest measured baseline length $(\sim 20 \mathrm{~km})$ in our network.

We have also used GIPSY-OASIS II software for GPS data processing for each experiment and the results were compared with GAMIT/GLOBK results. No considerable differences found between the two results (Yun and Hwang, 2002). Therefore, we chose the GAMIT/GLOBK result for further velocity solutions.

In the third step, we applied appropriate constraints to define reference frame of horizontal velocity fields (Dong et al., 1998) in a study area using GLOBK. Two kinds of velocity fields (Herring, 2003) were estimated from four sets of GPS data:

1) Horizontal velocities in ITRF2000 by minimizing the adjustments of ITRF2000 velocities of IGS stations used in analysis, and

2) Relative horizontal velocities between strands of the main fault with several options:

- Assuming 3 IGS stations: WUHN, SUWN, DAEJ, with NGA1, HAM1, and TAU1(2), locate on a single block (Michel et al., 2000, 2001; Feigl et al., 2003).

- Same as previous but at the local scale: excluding IGS stations.

- Minimum constraints also within a local frame: fix two stations on either side of the main fault.

- Fix three stations on either side of the main fault.

ITRF2000 velocity solution of our network can be checked by calculating the velocities of all sites using 
Table 1. Availability of GPS observations from Feb. 2002 to Mar. 2004

\begin{tabular}{|c|c|c|c|c|c|c|c|c|}
\hline & & NGA1 & DON1 & HAM1 & LEM1 & TAU1 & TAU2 & TAT1 \\
\hline \multirow[t]{5}{*}{$2002 a$} & 054 & $\mathrm{x}$ & $\mathrm{x}$ & $\mathrm{x}$ & $\mathrm{x}$ & & $\mathrm{x}$ & \\
\hline & 055 & $\mathrm{x}$ & $\mathrm{x}$ & $\mathrm{x}$ & $\mathrm{x}$ & & $\mathrm{x}$ & \\
\hline & 056 & $\mathrm{x}$ & $\mathrm{x}$ & $\mathrm{x}$ & $\mathrm{x}$ & & $\mathrm{x}$ & \\
\hline & 057 & $\mathrm{x}$ & $\mathrm{x}$ & $\mathrm{x}$ & $\mathrm{x}$ & & $\mathrm{x}$ & \\
\hline & 058 & $\mathrm{x}$ & $\mathrm{x}$ & $\mathrm{x}$ & $\mathrm{x}$ & & $\mathrm{x}$ & \\
\hline \multirow[t]{8}{*}{$2002 b$} & 318 & & $\mathrm{x}$ & & & $\mathrm{x}$ & & $\mathrm{x}$ \\
\hline & 319 & & $\mathrm{x}$ & & & & & $\mathrm{x}$ \\
\hline & 320 & & $\mathrm{x}$ & $\mathrm{x}$ & & & & \\
\hline & 321 & & $\mathrm{x}$ & $\mathrm{x}$ & $\mathrm{x}$ & & & \\
\hline & 323 & & & $\mathrm{x}$ & $\mathrm{x}$ & & & $\mathrm{x}$ \\
\hline & 324 & & & $\mathrm{x}$ & $\mathrm{x}$ & $\mathrm{x}$ & & \\
\hline & 325 & & & & $\mathrm{x}$ & $\mathrm{x}$ & & \\
\hline & 326 & & & & & $\mathrm{x}$ & $\mathrm{x}$ & $\mathrm{x}$ \\
\hline \multirow[t]{5}{*}{2003} & 051 & $\mathrm{x}$ & $\mathrm{x}$ & $\mathrm{x}$ & $\mathrm{x}$ & & $\mathrm{x}$ & \\
\hline & 052 & $\mathrm{x}$ & $\mathrm{x}$ & $\mathrm{x}$ & $\mathrm{x}$ & & $\mathrm{x}$ & \\
\hline & 053 & $\mathrm{x}$ & $\mathrm{x}$ & $\mathrm{x}$ & $\mathrm{x}$ & & $\mathrm{x}$ & \\
\hline & 054 & $\mathrm{x}$ & $\mathrm{x}$ & $\mathrm{x}$ & $\mathrm{x}$ & & $\mathrm{x}$ & \\
\hline & 055 & $\mathrm{x}$ & $\mathrm{x}$ & $\mathrm{x}$ & $\mathrm{x}$ & & $\mathrm{x}$ & \\
\hline \multirow[t]{7}{*}{2004} & 058 & $\mathrm{x}$ & $\mathrm{x}$ & $\mathrm{x}$ & $\mathrm{x}$ & & $\mathrm{x}$ & \\
\hline & 059 & $\mathrm{x}$ & $\mathrm{x}$ & $\mathrm{x}$ & $\mathrm{x}$ & & $\mathrm{x}$ & \\
\hline & 060 & $\mathrm{x}$ & $\mathrm{x}$ & $\mathrm{x}$ & $\mathrm{x}$ & & $\mathrm{x}$ & \\
\hline & 061 & $\mathrm{x}$ & $\mathrm{x}$ & $\mathrm{x}$ & $\mathrm{x}$ & & $\mathrm{x}$ & \\
\hline & 063 & & & & $\mathrm{x}$ & $\mathrm{x}$ & & $\mathrm{x}$ \\
\hline & 064 & & & & $\mathrm{x}$ & $\mathrm{x}$ & & $\mathrm{x}$ \\
\hline & 065 & & & & & $\mathrm{x}$ & $\mathrm{x}$ & $\mathrm{x}$ \\
\hline
\end{tabular}

Table 2. Mean WRMS for the shortest baselines from daily solutions and Precision of baseline length estimated from loosely constrained combination of sessions for individual campaigns.

\begin{tabular}{|c|c|c|c|c|c|c|}
\hline & \multirow{2}{*}{$\begin{array}{c}\text { Solution type } \\
\text { (Re-estimated orbit) }\end{array}$} & \multicolumn{3}{|c|}{ Mean Repeatability (mm) } & \multicolumn{2}{|c|}{ Precision of baseline length } \\
\hline & & North & East & Up & $\mathrm{a}(\mathrm{mm})$ & $\mathrm{b}(\mathrm{ppb})$ \\
\hline \multirow[t]{2}{*}{$2002 \mathrm{a}$} & bias-free & 1.7 & 3.8 & 13.6 & & \\
\hline & bias-fixed & 1.7 & 3.3 & 13.4 & 2.14 & 1.04 \\
\hline \multirow[t]{2}{*}{$2002 b$} & bias-free & 1.5 & 3.0 & 4.5 & & \\
\hline & bias-fixed & 1.6 & 1.7 & 5.0 & 1.50 & 0.95 \\
\hline \multirow[t]{2}{*}{2003} & bias-free & 2.6 & 3.5 & 13.4 & & \\
\hline & bias-fixed & 2.6 & 2.9 & 13.4 & 2.79 & 1.71 \\
\hline \multirow[t]{2}{*}{2004} & bias-free & 1.6 & 2.6 & 8.0 & & \\
\hline & bias-fixed & 1.6 & 2.7 & 8.1 & 2.16 & 1.54 \\
\hline
\end{tabular}

for example Sundaland platelet model from Michel et al. (2001).

Additionally, to better illustrate the deformation within the fault zone, strain rates of "eigenvalues" parameterization, the maximum extension $\varepsilon_{1}$, maximum compression $\varepsilon_{2}$ and its azimuth $\theta$, and rotation $\Omega$, were estimated for the whole network from the ITRF2000 velocity solution (Feigl et al., 1990; Yun, 2000). The advantage of using the strain parameters is that they are almost invariant to the changes in the horizontal network scale and orientation (Vanícek and Krakiwsky, 1986; Yun, 2000).

\section{Results}

The estimated velocities in ITRF2000 are shown in Table 3 and Fig. 1. ITRF2000 horizontal velocity field components of our network have uncertainties of about $\pm 3 \mathrm{~mm} / \mathrm{yr}$ except the east components at TAU1 and TAT1, which are \pm 3.5 and $\pm 3.8 \mathrm{~mm} / \mathrm{yr}$, respectively. It can be explained mainly by a rather small number of GPS data available, point centering by tripod, and type of antenna used in campaigns.

Velocities calculated by Sundaland platelet model (Michel et al., 2001) are shown in Fig. 1 and Table 3. They are well consistent with our ITRF2000 velocity solution. 
Table 3. Velocities estimated in ITRF2000 and by Michel et al. (2001).

\begin{tabular}{ccccc}
\hline & \multicolumn{2}{c}{ ITRF2000 } & \multicolumn{2}{c}{ Michel et al. (2001) } \\
& VE $(\mathrm{mm})$ & VN $(\mathrm{mm})$ & VE $(\mathrm{mm})$ & VN $(\mathrm{mm})$ \\
\hline DAEJ & $28.1 \pm 0.9$ & $-16.0 \pm 0.9$ & & \\
SUWN & $28.0 \pm 0.9$ & $-15.2 \pm 0.9$ & & \\
WUHN & $32.8 \pm 0.9$ & $-13.5 \pm 0.9$ & & \\
NGA1 & $41.1 \pm 3.0$ & $-9.0 \pm 2.6$ & 36.1 & -9.2 \\
HAM1 & $35.4 \pm 3.0$ & $-10.7 \pm 2.6$ & 36.1 & -9.2 \\
TAU1 & $35.6 \pm 3.5$ & $-11.1 \pm 3.0$ & 36.0 & -9.1 \\
TAU2 & $35.2 \pm 3.1$ & $-10.6 \pm 2.6$ & 36.0 & -9.2 \\
DON1 & $36.9 \pm 3.0$ & $-11.4 \pm 2.6$ & 36.0 & -9.2 \\
LEM1 & $36.6 \pm 3.0$ & $-10.5 \pm 2.6$ & 36.1 & -9.2 \\
TAT1 & $35.3 \pm 3.8$ & $-8.8 \pm 3.0$ & 36.1 & -9.2 \\
\hline
\end{tabular}

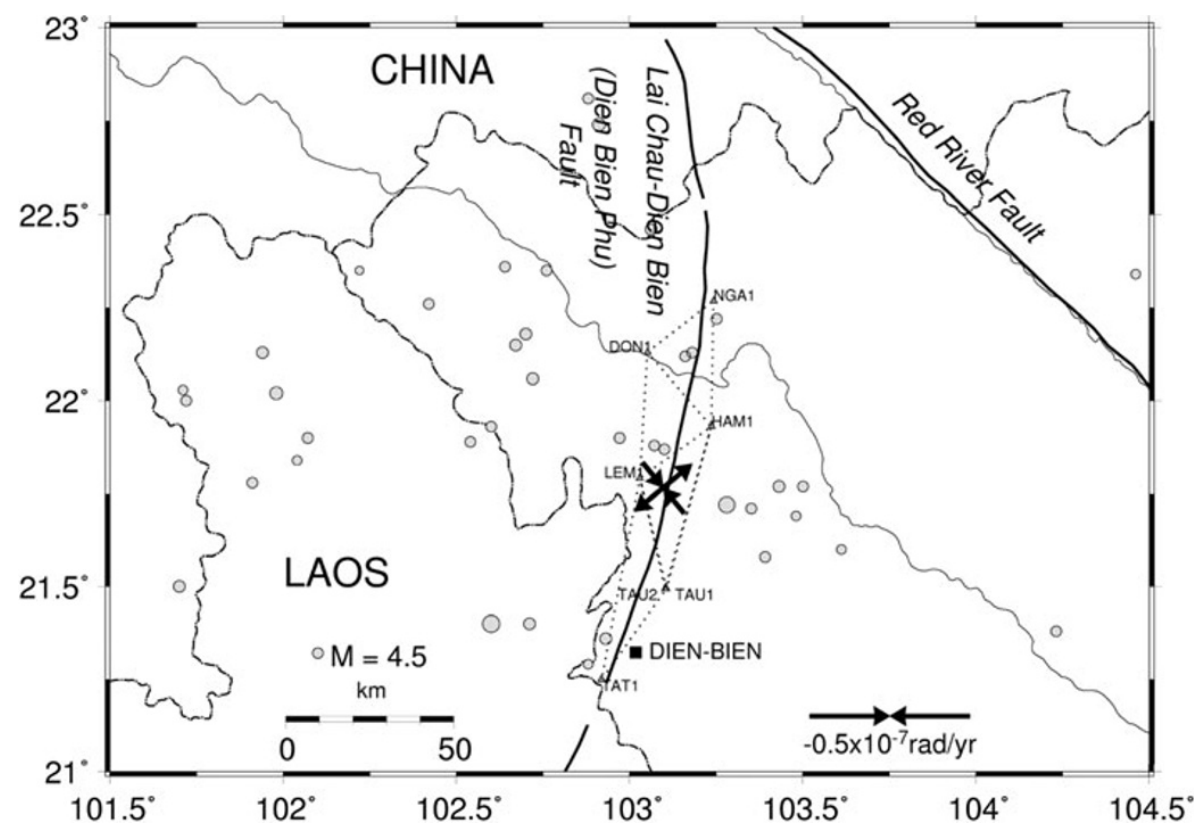

Fig. 3. GPS network, earthquake epicenters, faults, rivers, international borders are the same as in Fig. 2, and the maximum extension, compression strain parameters estimated from our ITRF2000 velocity solution for the whole network.

Every estimated local horizontal velocity had the same uncertainty as the ITRF2000 solution. Most of these velocities were several millimeters/yr and at $95 \%$ confidence level, resulted in no displacement between the strands of the main fault, except NGA1 station, which gave a remarkable north-eastward, greater-than-5 mm/yr velocity (solutions with minimum constraints: fixing DON1 and LEM1 stations, and fix three stations DON1, LEM1, TAT1 on one side of the fault (Fig. 2). This result reconfirms the abovementioned point of view of Michel et al. (2000, 2001), and favors the left-lateral strike-slip of the fault zone (Nguyen Van Hung and Hoang Quang Vinh, 2001).

Concerning the whole network, the values of the most extensional, compressional, and rotational parameters are also insignificant and smaller than their standard errors. None of them were distinguishable from zero (no deformation) with $95 \%$ confidence.
However, based on their direction, the estimated strain rates can be interpreted in terms of the fault's present-day activity. Figure 3 shows the estimated strain rates $\varepsilon_{1}, \varepsilon_{2}$ from the ITRF2000 velocity solution. Azimuths of them correspond to maximum left-lateral simple shear on the sublongitudinal striking LC-DBF. The maximum compression strain rate almost coincides with north-northwest trending compression at late stage of tectonic stress field of the LCDBF, which started, possibly, from Pliocene, 5 Ma ago (Nguyen Van Hung and Hoang Quang Vinh, 2001; Burchfiel, 2004). Meanwhile, vertical velocity component was not precise enough for the detection of the reverse or normal faulting in a study area.

\section{Conclusion}

A series of GPS measurements for four epochs from 2002 to 2004 were used to detect the recent crustal movements 
in a local geodetic network spanning LC-DBF in Northwest of Vietnam. For crustal movement study cases, our ITRF2000 and local horizontal velocity solutions had only average precision, and any horizontal movement components smaller than $3 \mathrm{~mm} / \mathrm{yr}$ could not be detected. On the basis of such level of precision and quantity of acquired data, we could only conclude that there were not much significant local displacement and deformation in the whole network at 95\% confidence level between 2002 and 2004. In other words, present-day activities of the fault can be described as follows:

1) The LC-DBF system is most likely to be active in the present day as a left-lateral strike-slip fault as discussed by Nguyen Van Hung and Hoang Quang Vinh (2001), and Burchfiel (2004).

2) From a regional point of view, LC-DBF system on Sundaland, that is, Indochina, together with South-China are moving east-southeastward (Michel et al., 2000, 2001).

In order to improve the precision of velocity solution, more GPS campaigns must be carried out with use of an appropriate antenna and denser site distribution along the fault zone and its profile. With such velocity field, some models such as the simple elastic dislocation model can be applied for further interpretation of the recent activity of the LC-DBF.

Acknowledgments. The authors are grateful to Ha Minh Hoa and Nguyen Ngoc Thuy for initiating the joint project, which collected GPS data for this work. They thank all the colleagues from the Institute of Geological Science, Vietnamese Academy of Science and Technology, and Vietnam Research Institute of Land Administration who seriously and joyfully participated in field reconnaissance, establishing benchmarks, and GPS campaigns. Nguyen Van Hung and Hoang Quang Vinh kindly provided their detailed results concerning LC-DBF. Figures of this work were produced with the public-domain GMT software (Wessel and Smith, 1998). This study was supported by a post-doc fellowship from Korea Science and Engineering Foundation and a grant from the Natural Science Council of Vietnam.

\section{References}

Altamimi, Z., P. Sillard, and C. Boucher, ITRF2000: A new release of the International Terrestrial Reference Frame for Earth Science Application, J. Geophys. Res., 107(B10), 2214, doi: 10.1029/2001JB000561, 2002.

Becker, M., E. Reinhart, Soeb Bin Nordin, D. Angermann, G. Michel, and Ch. Reigber, Improving the velocity field in South and South-East Asia: The third round of GEODYSSEA, Earth Planets Space, 52, 721-726, 2000.

Burchfiel, B. C., 2003 presidential address: New technology; new geological challenges, GSA Today, 14(2), 4-10, 2004.

DeMets, C., R. G. Gordon, D. F. Argus, and S. Stein, Effect of recent revisions to the geomagnetic reversal time scale on estimates of current plate motions, Geophys. Res. Lett., 21, 2191-2194, 1994.

Dong, D., T. A. Herring, and R. W. King, Estimating regional deformation from a combination of space and terrestrial geodetic data, Journal of Geodesy, 72, 200-214, 1998

Feigl, K. L., R. W. King, and T. H. Jordan, Geodetic measurement of tectonic deformation in the Santa Maria fold and thrust belt, California, J. Geophys. Res., 95, 2679-2699, 1990.

Feigl, K. L., Duong Chi Cong, M. Becker, Tran Dinh To, K. Neumann, and Nguyen Quang Xuyen, Insignificant horizontal strain across the Red River fault near Thac Ba, Vietnam from GPS measurements 1994-2000, Geophysical Research Abstracts, Vol. 5, 04707, EGS-AGU-EUG Joint Assembly, Nice, France, 6-11 April 2003.

Ha Minh Hoa, Tran Dinh To, Duong Chi Cong, Vy Quoc Hai, Nguyen
Ngoc Lau, and others, Application of GPS for Studying Crustal Movements and the First Results of Recent Displacement of Lai Chau-Dien Bien Fault Zone from Feb. 2002 to Feb. 2003, Scientific Report, Hanoi, 2003.

Herring, T. A., GLOBK: Global Kalman filter VLBI and GPS analysis program, version 10.1, MIT, Cambridge, 2003.

Holt, W. E., N. Chamot-Rooke, X. Le Pichon, A. J. Haines, B. Shen-Tu, and J. Ren, Velocity field in Asia inferred from Quaternary fault slip rates and Global Positioning System observations, J. Geophys. Res., 105(B8), 19,185-19,209, 2000.

King, R. W. and Y. Bock, Documentation for the GAMIT GPS analysis software, release 10.1, MIT, Cambridge, 2003.

King, R. W., F. Shen, B. C. Burchfiel, L. H. Royden, E. Wang, Z. Chen, Y. Liu, X. Y. Zhang, J. X. Zhao, and Y. Li, Geodetic measurement of crustal motion in southwest China, Geology, 25(2), 179-182, 1997.

Lacassin, R., H. Maluski, P. H. Leloup, P. Tapponnier, Chaiyan Hinthong, Kanchit Siribhakdi, Saengathit Chuaviroj, and Adul Charoenravat, Tertiary diachronic extrusion and deformation of western Indochina: Structural and 40Ar/39Ar evidence from NW Thailand, J. Geophys. Res., 102(B5), 10,013-10,037, 1997.

Larson, K. M. and D. C. Agnew, Application of the Global Positioning System to crustal deformation measurement: 1. Precision and Accuracy, J. Geophys. Res., 96, 16,547-16,565, 1991.

McCarthy, D. D., IERS Technical Note 21, U.S. Naval Observatory, 1996. Michel, G. W., M. Becker, D. Angermann, Ch. Reigber, and E. Reinhart, Crustal motion in E- and SE-Asia from GPS measurements, Earth Planets Space, 52, 713-720, 2000.

Michel, G. W., Yue Qui Yu, Sheng Yuan Zhu, Ch. Reigber, M. Becker, E. Reinhart, W. Simons, B. Ambrosius, Ch. Vigny, N. Chamot-Rooke, X. Le Pichon, P. Morgan, and S. Matheussen, Crustal motion and block behaviour in SE-Asia from GPS measurements, Earth. Planet. Sci. Lett., 178, 239-244, 2001.

Nguyen Ngoc Lau, Relationship between satellite cut-off angle and elevation accuracy in GPS measurement technique, Journal of GeodesyCartography, Vietnamese Society of Geodesy-Cartography, and Remote Sensing, No. 1, p. 35-47, Hanoi, 2002a.

Nguyen Ngoc Lau, Role of atmospheric in high precision GPS data processing, Journal of Geodesy-Cartography, Vietnamese Society of Geodesy-Cartography, and Remote Sensing, No. 2, p. 41-53, Hanoi, 2002 b.

Nguyen Van Hung and Hoang Quang Vinh, Moving characteristics of the Lai Chau-Dien Bien Fault zone during Cenozoic, Journal of Geology, Series B, No. 17-18, p. 65-77, Hanoi, 2001.

Rothacher, M. and G. Mader, Combination of antenna phase center offsets and variations: Antenna calibration set IGS_01, http://www.aiub.unibe. ch, 1996.

Vanícek, P. and E. J. Krakiwsky, Geodesy: The Concepts, 2nd ed., NorthHolland, 697 pp., 1986.

Wang, Q., P. Z. Zhang, J. T. Freymueller, R. Bilham, K. M. Larson, X. Lai, X. You, Z. Niu, J. Wu, Y. Li, J. Liu, Z. Yang, and Q. Chen, Present-day crustal deformation in China constrained by Global Positioning System measurements, Science, 294, 574-577, 2001.

Wessel, P. and W. H. F. Smith, New, improved version of Generic Mapping Tools released, EOS Trans. Amer. Geophys. U., 79(47), 579, 1998.

Yun Hong Sic, Application of two dimensional filtering technique for the precision calculation of crustal deformation parameters, Journal of Korean Society of Surveying, Geodesy, Photogrammetry, and Cartography, 018(001), 75-83, 4/2000.

Yun Hong Sic and Hwang Jin Sang, Determination of absolute coordinates of permanent GPS site, Journal of Korean Society of Surveying, Geodesy, Photogrammetry, and Cartography, 019(004), 415-423, $12 / 2001$.

Yun Hong Sic and Hwang Jin Sang, Comparison of positioning algorithms of GPS data processing software for analyzing the ultra long baseline, Journal of the Korean Society of Civil Engineers, 22(3-D), 571-582, $5 / 2002$.

Zhang, Q. and W. Zhu, The initial establishment of the tectonic block motion model of China from space geodetic data, Chinese Science Bulletin, 45(16), 1523-1528, 2000.

C. C. Duong (e-mail: dccong1@yahoo.com), H.-S. Yun (e-mail: yhs@geo.skku.ac.kr), and J.-M. Cho (e-mail: jmcho@geo.skku.ac.kr) 